\title{
VARIABILITY IN THE LIGNINOLYTIC ENZYMES ACTIVITY BY LENTINULA EDODES IN SUBMERGED CULTURE WITH LIGNIN AND GLUCOSE
}

\author{
${ }^{1,4}$ Citlalli Harris-Valle, ${ }^{2}$ Elisa Valenzuela-Soto, ${ }^{1}$ Alfonso Sánchez, \\ ${ }^{3}$ Rigoberto Gaitán-Hernández and ${ }^{1}$ Martín Esqueda \\ ${ }^{1}$ Coordinación de Tecnología de Alimentos de Origen Vegetal, \\ ${ }^{2}$ Coordinación de Ciencia de los Alimentos, \\ Centro de Investigación en Alimentación y Desarrollo, A.C. (CIAD), Hermosillo, Sonora, México \\ ${ }^{3}$ Instituto de Ecología, A.C., Xalapa, Veracruz, México \\ ${ }^{4}$ Instituto Tecnológico Superior de Zacapoaxtla, Zacapoaxtla, Puebla, Mexico
}

Received 2014-01-03; Revised 2014-04-24; Accepted 2014-04-28

\begin{abstract}
The white-rot basidiomycete Lentinula edodes is the second most edible mushroom cultivated on the world. This fungus decomposes cell-wall associated macromolecules, is a natural degrader of lignin polymers. The differences in enzyme activities between strains of $L$. edodes provided useful information about the participation of enzymes in different development stages of the fungus. The effect of lignin on the fungal biomass production and activity behavior of ligninolytic enzymes when L. edodes is cultivated in a medium containing lignin with and without glucose as a carbohydrate source was tested. When glucose was present in the culture, lignin increase the mycelial biomass by $70 \%$ at 22 days compared to the control culture. The lignin media without glucose affected mycelial growth up to $20 \%$ less that the control without lignin and glucose. The activity of laccase, lignin peroxidase, aryl alcohol oxidase, manganese dependent peroxidase and catalase was modified depending on whether the medium had lignin and glucose, or lignin alone. A carbohydrate source is important to fungal growth, but the dissolution of lignin monomers might switch the signal that controls growth rate and enzymatic activity.
\end{abstract}

Keywords: Shiitake, Laccase, Lignin Peroxidase, Aryl Alcohol Oxidase, Manganese Dependent Peroxidase, Catalase

\section{INTRODUCTION}

Lentinula edodes (Berk) Pegler is considered an alternative recycling agent for agricultural wastes and there have been several studies to understand the relationship between its growth and ligninolytic activity. L. edodes produces high amounts of hydrolases and oxidases for bioconversion of lignocellulosic wastes. The differences in enzyme activities among strains of L. edodes provided useful information about the participation of enzymes in different development stages (Silva et al., 2005; Philippoussis et al., 2011).
Lignin is a complex macromolecule that occurs in the cell walls of vascular plants. This polymer is considered recalcitrant because it breaks down more slowly than other wood polymers (hemicellulose, cellulose). Nevertheless, there are some fungi species capable of completely degrading lignin to carbon dioxide and water (Elisashvili and Kachlishvili, 2009; Busse et al., 2013). L. edodes is a white-rot fungus that can depolymerize lignin by means of an oxide-reduction mechanism called ligninolysis. This process occurs in two stages. First the subunit bonds are broken by Lignin Peroxidase (LiP) or Manganese Peroxidase (MnP) using en Alimentación y Desarrollo, A.C. (CIAD), Hermosillo, Sonora, México 
$\mathrm{H}_{2} \mathrm{O}_{2}$ as the oxidative cofactor. The same enzymes are capable of producing $\mathrm{H}_{2} \mathrm{O}_{2}$ from reductants such as Glutathione (GSH) using $\mathrm{O}_{2}$ as oxidant. During depolymerization oligomers of lignin and chemically stable phenolic monomers are produced (Aro et al., 2005; Elisashvili and Kachlishvili, 2009).

During the second phase of ligninolysis, phenoxy radicals are converted into chemically stable products by oxidases and oxido-reductases (v.g., Aryl Alcohol Oxidases (AAO) and laccase) (Guillén et al., 2000). Additionally, AAO can oxidize different alcohols, producing Reactive Oxygen Species (ROS) that can be used by peroxidases to initiate the oxido-reduction mechanism as a cycle (Guillén and Evans, 1994).

Some authors have found that lignin derivatives enhanced the mycelial growth in white-rot fungi, whereas lignin or compounds related to lignin subunits induce the lignin degrading system (Beltrán-García et al., 2001; Ferrara et al., 2002). However, the relationship between fungal growth and modification of activity of the principal ligninolytic enzymes (LiP, MnP, AAO and laccase) when lignin polymer is added to culture medium is not clear. It has been proposed that lignin is broken down when cultures of P. chrysosporium and $L$. edodes enter the stationary phase and nutrient levels are low (Ohga and Royse, 2001).

Nevertheless, in young cultures of $L$. edodes high ligninolytic activity has been observed to coincide with the active degradation of carbohydrate sources are actively because the organisms require an alternative substrate in order to continue breaking down the lignin (Leatham, 1985; Mata et al., 1997). The paper describes LiP, MnP, AAO and laccase production profiles and induction in liquid cultures of $L$. edodes by the presence of glucose and lignin in the growth medium to know about enzymatic modulation. The hypothesis of this study is that lignin and glucose together supplemented in a liquid culture medium of L. edodes enhanced biomass and modified the activity pattern of ligninolytic enzymes.

\section{MATERIALS AND METHODS}

\subsection{Culture Conditions}

Lentinula edodes commercial strain (IE-105) was provided from Fungi Strain Collection of the Institute of Ecology (Xalapa, Mexico) (CS2: Original Code from Fungi Perfecti). The fungus was maintained on Potato-Dextrose-Agar (PDA) (DIFCO) (20 g dextrose, $4 \mathrm{~g}$ potato infusion and $15 \mathrm{~g}$ agar per liter) at $4^{\circ} \mathrm{C}$. Mycelial inocu-lum ( $1 \mathrm{~cm} \varnothing$; cut along the edge of a 10-day-old actively growing colony) was transferred from a stock plate (PDA) to submerged cultures (4 $\mathrm{mL}$ ) at $3.4 \mathrm{~g}$ in an orbital shaker (Lab-Line Instruments) at $25^{\circ} \mathrm{C}$ in the dark, using a $20 \mathrm{~mL}$ cotton-plugged flask scintillation vials.

The effect of lignin concentration in biomass production after 12 days of $L$. edodes culture was assayed to a concentration of $0,0.25,0.5,0.75,1.0,1.5$ and $2.0 \mathrm{mg} \mathrm{mL}^{-1}$. The highest biomass production was obtained by adding $1 \mathrm{mg}$ of lignin $/ \mathrm{mL}$. Therefore the treatments were carried out without lignin and adding 1 $\mathrm{mg}$ of alkali lignin/mL with Mw 28,000 (Aldrich No. Cat. 37095-9) to media [glucose/peptone (40:10 w/v), $\mathrm{pH}$ 4.5] (LGP). Additionally, a liquid medium without glucose (1 mg peptone/mL and $1 \mathrm{mg}$ lignin/mL) (LP) and other with glucose and without lignin (glucose/peptone (40:10 w/v), $\mathrm{pH}$ 4.5) (GP) were prepared. The solution was sterilized at $120^{\circ} \mathrm{C}$ for 30 min prior to inoculation. The glucose was sterilized separately to avoid the melanins formation.

\subsection{Fungal Biomass and Enzyme Extract}

To determine biomass production, samples were taken every 2 days, during 22 days, after 4 days of incubation. The fungal biomass was harvested by filtration through Whatman No 1 filter, was washed with $500 \mathrm{~mL}$ of distilled water and dried at $60^{\circ} \mathrm{C}$ for $24 \mathrm{~h}$ and weighed. The extracellular proteins, contained in $3 \mathrm{~mL}$ of aqueous residue culture, were concentrated by precipitation with acetone $(1: 5, \mathrm{v} / \mathrm{v})$. The aqueous residue culture came from the same samples used for biomass quantification. The solution was cooled at $-20^{\circ} \mathrm{C}$ for $6 \mathrm{~h}$ and centrifuged $(10 \mathrm{~min}$ at $2582 \mathrm{~g}$ in Sorvall $\mathrm{RC} 5 \mathrm{~S}$ rotor SA-600) at room temperature $\left(25^{\circ} \mathrm{C}\right)$. The pellet was suspended in $300 \mu \mathrm{L}$ of $50 \mathrm{mM}$ sodium acetate and $10 \mathrm{mM} \mathrm{KCl}$ buffer, $\mathrm{pH} 4$ (adding $250 \mu \mathrm{M}$ of phenyl-methyl-sulfonyl-fluoride as a protease inhibitor). The extracellular protein samples were kept at $-80^{\circ} \mathrm{C}$ for enzymatic assays. Three replicates were prepared and conducted in parallel. Independent cultures (3-6 flasks) were used for each replicate. The results are reported as the mean with its standard deviation.

\subsection{Enzyme Analyses}

Mn-dependent peroxidase (EC 1.11.1.13) activity was measured by monitoring the formation of Mn IIImalonate complex at $270 \mathrm{~nm}$ during one minute in presence of $0.1 \mathrm{mM} \mathrm{H}_{2} \mathrm{O}_{2}\left({ }_{\varepsilon 270}=11.59 \mathrm{M}^{-1} \mathrm{~cm}^{-1}\right)$, using $0.5 \mathrm{mM} \mathrm{MnSO}_{4}$ and $50 \mathrm{mM}$ sodium malonate $(\mathrm{pH} 4.5)$ (Faison and Kirk, 1985). Aryl alcohol oxidase (EC 1.1.3.7) was determined by the method of Guillén et al. (1992) using $5 \mathrm{mM}$ veratryl alcohol in $100 \mathrm{mM}$ sodium 
phosphate buffer ( $\mathrm{pH}$ 6.0) and lignin peroxidase (EC 1.11.1.14) activity assay mixture contained $25 \mathrm{mM}$ sodium tartrate ( $\mathrm{pH} 3.0), 2 \mathrm{mM}$ veratryl alcohol and 0.1 $\mathrm{mM} \mathrm{H} \mathrm{H}_{2} \mathrm{O}_{2}$ (Tien and Kirk, 1984). Both activities were measured by monitoring the increase in absorbance at $310 \mathrm{~nm}\left({ }_{\varepsilon 310}=9300 \mathrm{M}^{-1} \mathrm{~cm}^{-1}\right)$.

Laccase activity (EC 1.10.3.2) was estimated by monitoring at $420 \mathrm{~nm}\left({ }_{\varepsilon 420}=36 \mathrm{M}^{-1} \mathrm{~cm}^{-1}\right)$ (Boer et al., 2004) the time oxidation of $0.3 \mathrm{mM}$ ABTS (2, 2'azinobis-3-ethyl--benzothiazoline--6-sulphonic acid) in $50 \mathrm{mM}$ sodium malonate buffer ( $\mathrm{pH} 4.5$ ). Catalase activity (EC 1.11.1.6) was assayed by measuring the degradation $\mathrm{H}_{2} \mathrm{O}_{2}(10 \mathrm{mM})$ in $100 \mathrm{mM}$ potassium phosphate buffer $(\mathrm{pH} 7.8)$. The rate of disappearance was monitored at $240 \mathrm{~nm}$ (Cohen et al., 1970).

Enzyme assays were carried out at room temperature $\left(25^{\circ} \mathrm{C}\right)$ using a Cari 50 Bio spectrophotometer (Varian, Sugarland Tex.) during all incubation period. To start measurements, $10 \mu \mathrm{L}$ of extracellular protein sample was added to $90 \mu \mathrm{L}$ of reaction mixture (specific substrate dissolved in the buffer). One unit of enzyme activity was defined as $1 \mu \mathrm{moL}$ of product formed per min per $\mathrm{mg}$ of protein (U/mg of protein). Extracellular protein concentration was determined using Bradford's method (Bradford, 1976) using Bovine Serum Albumin (BSA) as standard. All assays were done in triplicate.

A completely randomized design was applied to enzyme analyses. Treatments were tested by triplicate. Independent variable was lignin and glucose and dependent variable the different enzymatic activities.

\section{RESULTS}

\subsection{Biomass Production}

Different concentrations of lignin were tested for their efficiency in stimulating biomass production. It was found that the highest mycelial growth was obtained by adding $1 \mathrm{mg}$ of lignin/mL to the culture prepared with glucose and peptone (data not shown). Therefore, this concentration was selected for the analysis of enzyme activity. In the culture without glucose the mycelial biomass was not affected compared to with glucose even though it decreased $20 \%$ at the beginning and the end of the culture period (Fig. 1A). When the fungus was cultivated in a medium containing Lignin and GlucosePeptone (LGP), mycelial growth was increased 45-70\% compared to that of the Glucose-Peptone medium without lignin (GP), 14 days after inoculation (Fig. 1B).

When glucose was present in the medium, the extracellular protein concentration increased during fermentation. The highest levels were detected in LGP (ca.
$40 \%$ higher than that of GP after 12 days of incubation). However, the protein concentration in Lignin and Peptone (LP) was similar to that of GP from days 4 to 14 and then decreased to lower levels ( $80 \%$ less than that of GP) compared to the other cultures (Table 1).

\subsection{Enzymatic Activity}

The activity of the four ligninolytic enzymes was detected in GP earlier than in LGP (Fig. 2). The activity levels of laccase, MnP and LiP in GP were higher than in LGP throughout the culture period; only AAO activity was higher in LGP on days 4, 10, 12 and 22.

On comparing different treatments, ligninolytic activity levels found in LP were approximately 10 times higher than those of LGP with the exception of MnP activity which was no longer detectable (Fig. 3).

The activity pattern of catalase was similar in GP and LGP, as it was high earlier in the culture period and decreased during incubation. Nevertheless, catalase activity in LGP was 55-70\% higher than in GP for the first 8 days of culture. The highest activity levels of catalase occurred in LP (twice that of GP and LGP) 20 days after inoculation (Fig. 4).

The patterns of ligninolytic enzyme activities measured in LGP are shown in Fig. 2. The first activity detected was that of AAO (0.018 U/mg of protein). After 10 days, a second peak in AAO activity was detected and LiP activity increased, reaching its maximum at 12 days (0.006 U/mg of protein). Laccase activity peaked immediately after AAO activity declined (at 14 days), whereas LiP remained fairly constant for 10 days. When LiP and laccase activity levels gradually decreased (day 18), MnP activity increased and reached its maximum activity level $(0.015 \mathrm{U} / \mathrm{mg}$ of protein) on the last day of incubation (day 22).

Table 1. Ratio of change in extracellular protein concentration vs. biomass production during 22 days of L. edodes culture.

Extracellular protein concentration/biomass

\begin{tabular}{|c|c|c|c|}
\hline \multirow[b]{2}{*}{ Time (days) } & \multicolumn{3}{|c|}{ 111 } \\
\hline & GP & LGP & LP \\
\hline 4 & 0.23 & 0.05 & 1.30 \\
\hline 6 & 0.45 & 0.17 & 1.12 \\
\hline 8 & 0.22 & 0.03 & 0.98 \\
\hline 10 & 0.62 & 0.42 & 0.22 \\
\hline 12 & 0.58 & 0.77 & 0.63 \\
\hline 14 & 0.70 & 0.82 & 0.85 \\
\hline 16 & 1.25 & 1.09 & 0.12 \\
\hline 18 & 1.40 & 1.17 & 0.17 \\
\hline 20 & 1.05 & 1.05 & 0.50 \\
\hline 22 & 1.11 & 1.16 & 0.53 \\
\hline
\end{tabular}




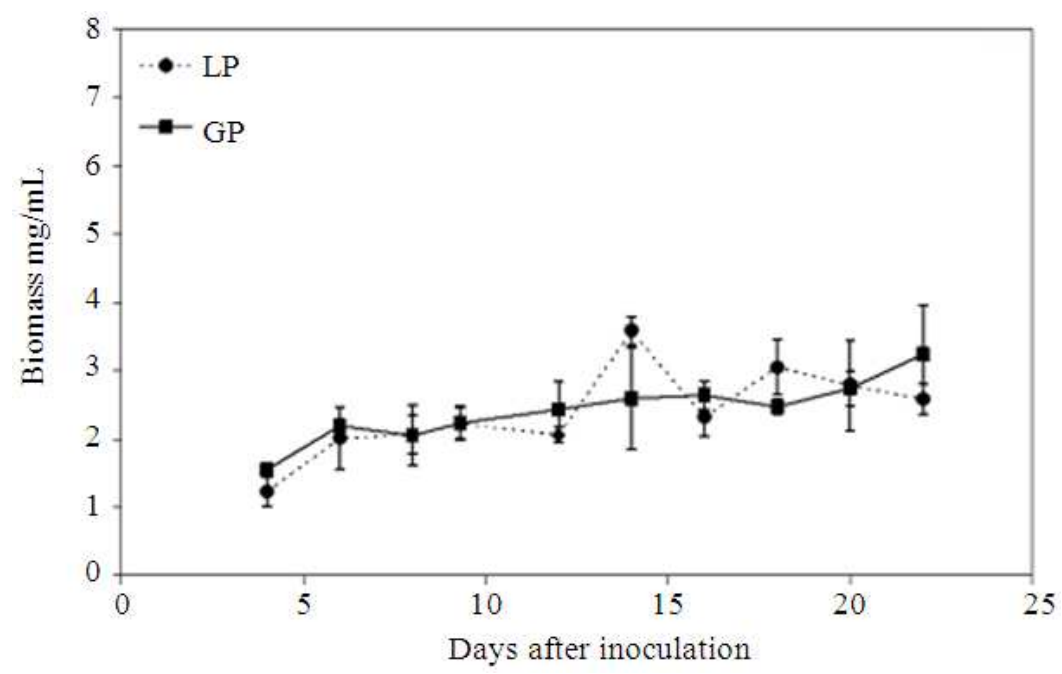

(A)

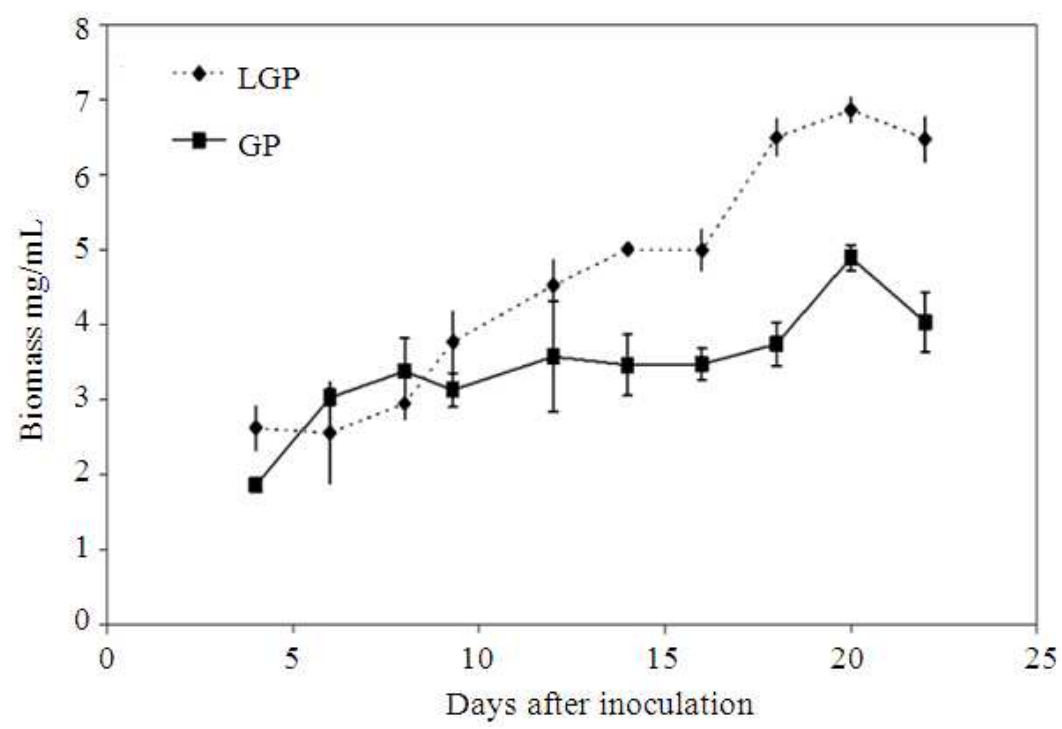

(B)

Fig. 1. The effect of culture conditions on the biomass of L. edodes with (A) lignin-peptone LP (•), glucose-peptone GP (घ) and (B) lignin-glucose-peptone LGP $(\bullet)$ added to the culture medium. Each point is the mean \pm standard deviation. The experiment was carried out in independent

The levels of LiP and MnP activity detected in LGP were lower than those of GP for all the days sampled (Fig. 2). Figure 3 shows that over 14 days of incubation in LP medium, enzyme activity was not detectable (except on day 8 , when LiP activity was $0.1 \mathrm{U} / \mathrm{mg}$ of protein). The highest LiP and AAO activities were detected at the same time $(4.32$ and $0.025 \mathrm{U} / \mathrm{mg}$ of protein, respectively on day 16). After the activity of both enzymes decreased, laccase activity increased to $0.74 \mathrm{U} / \mathrm{mg}$ of protein on day 20 .
In $\mathrm{GP}, \mathrm{LiP}$ was the first enzyme for which activity was detected $(0.2 \mathrm{U} / \mathrm{mg}$ of protein 8 days after incubation), followed by $\mathrm{AAO}, \mathrm{MnP}$ and laccase activities that gradually increased, reaching their maximum level on day $10(0.01,0.01$ and $0.08 \mathrm{U} / \mathrm{mg}$ of protein, respectively) (Fig. 3). After that, LiP activity decreased and stayed constant and then surprisingly peaked again on the last day of incubation $(0.25 \mathrm{U} / \mathrm{mg}$ of protein). 
Citlalli Harris-Valle et al. / American Journal of Agricultural and Biological Sciences 9 (3): 369-378, 2014

Citlalli Harris-Valle et al. / American Journal of Agricultural and Biological Sciences 9 (3): 369-378, 2014



Fig. 2. The effect of culture conditions on enzyme activity of L. edodes (laccase-LAC; aryl alcohol oxidase-AAO; lignin peroxidaseLiP; and manganese peroxidase-MnP) with lignin-glucose-peptone LGP ( $\mathbf{\Delta})$ and glucose-peptone GP (๘) added to culture medium. Each point is the mean \pm standard deviation
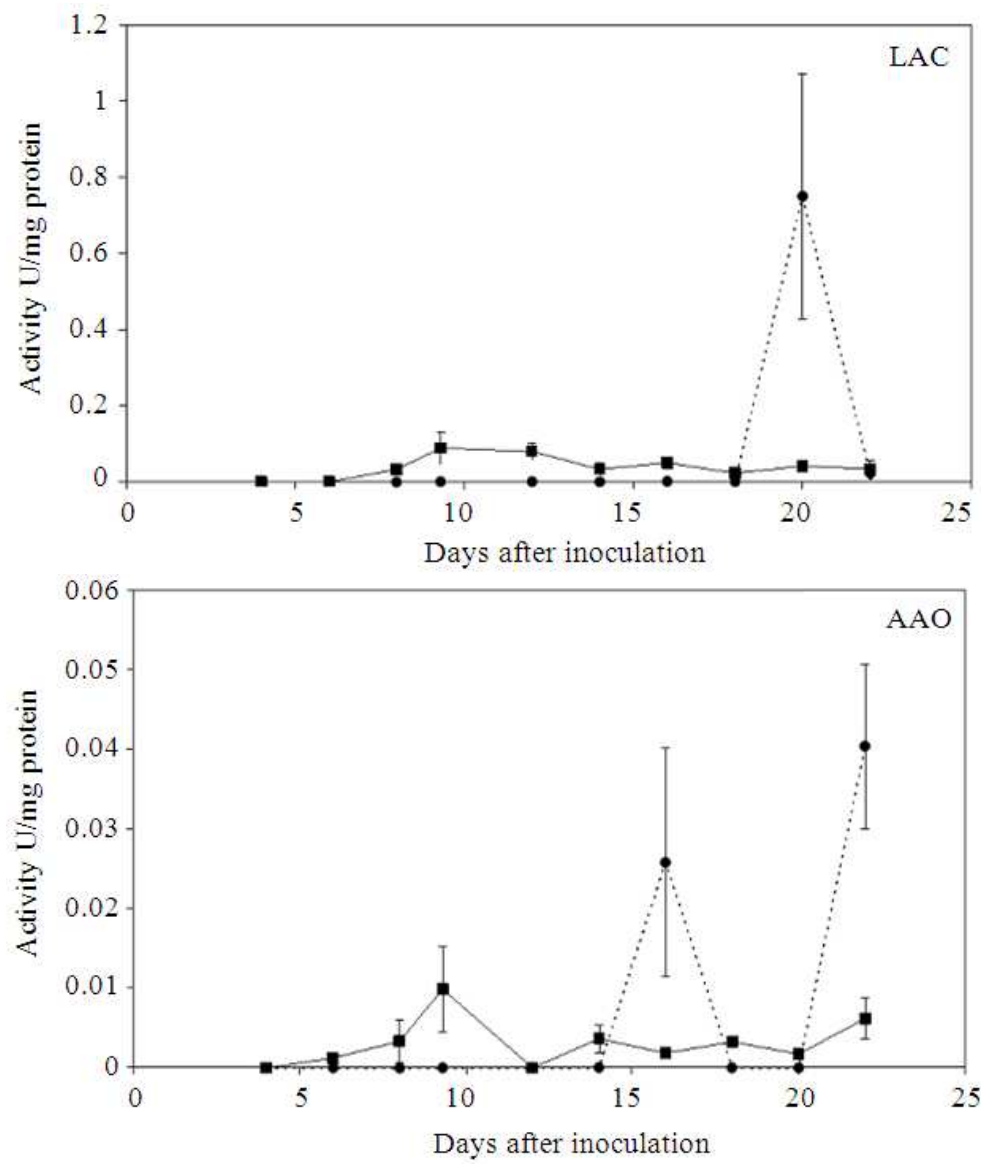

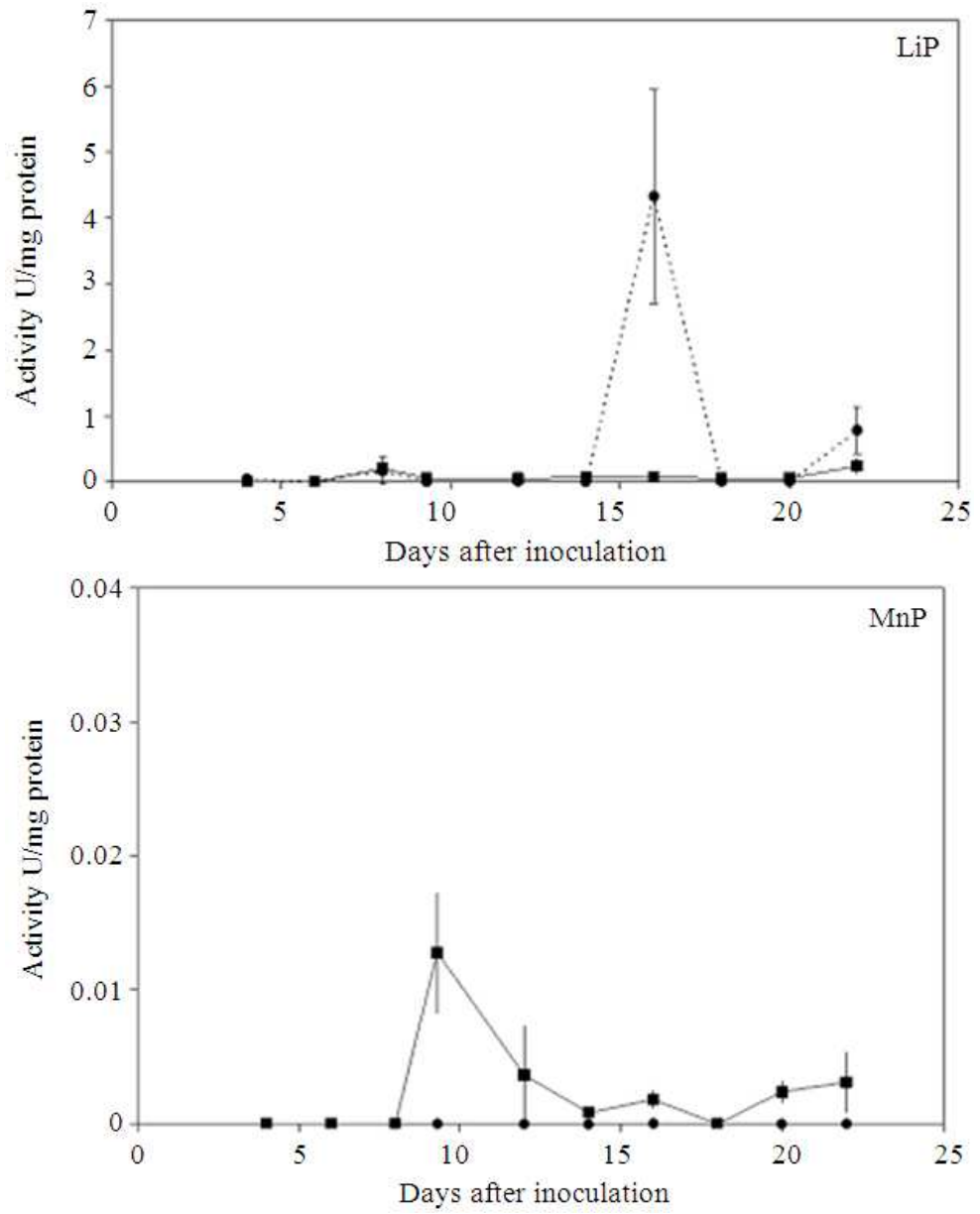

Fig. 3. Ligninolytic enzymes activity (laccase-LAC; aryl alcohol oxidase-AAO; lignin peroxidase-LiP; and manganese peroxidase-MnP) of L. edodes on two culture medium with lignin-peptone LP (•) and glucose-peptone GP (ロ). Each point is the mean \pm standard deviation

Figure 2 and 4 show a decrease in catalase activity once the activity of both peroxidases ( $\mathrm{MnP}$ and $\mathrm{LiP})$ increase in the GP and LGP treatments. A contrary effect was found in LP cultures (Fig. 3-4): Catalase activity was gradually increased to higher levels and $\mathrm{MnP}$ activity remained undetected. In the same treatment (LP), LiP activity peaked before catalase reached its maximum activity level and there was a slight increase in LiP when catalase activity decreased (Fig. 3-4).

\section{DISCUSSION}

\subsection{Biomass Production}

It has been established that lignin derived phenols and polymeric lignin play a role in stimulating growth in white-rot fungi, including L. edodes (Beltrán-García et al.,
2001; Ferrara et al., 2002). A similar effect was observed in biomass production in the treatment containing Lignin and Glucose (LGP). Nevertheless, when glucose was absent from the medium supplied with Lignin (LP), biomass production was not different from that of the cultures without lignin (GP) (Fig. 1A).

In general, biomass production was similar in the GP and LP cultures, while the enhancement of fungal growth was observed when lignin and glucose were added to the medium. This indicates that a simple carbon source combined with lignin had a positive effect on the mycelial biomass. It was not possible to know whether L. edodes used lignin as the carbon source or if lignin was simply a growth promoter. However, there was an increase of biomass and that is probably a result of the solubilization of lignin monomers. 



Fig. 4. Catalase activity of L. edodes on lignin-glucose-peptone LGP ( $\bullet$, glucose-peptone GP (•) and lignin-peptone LP (•) culture medium. Each point is the mean \pm standard deviation

\subsection{Enzymatic Activity}

Some experiments have demonstrated that when added to the culture medium, polymeric lignin and different aromatic and phenolic molecules (derived from or related to lignin) enhance the activity and transcript levels of laccase in different fungi (Tychanowicz et al., 2004; Covallazzi et al., 2005; Salmones and Mata, 2005). Additionally, it has been proposed that laccase induction stops when the glucose has been consumed and when compounds have been solvated or liberated during lignin degradation (Ha et al., 2001; Moldes et al., 2004). The results presented in Fig. 2 do not agree with those mentioned above because laccase activity was lower in LGP than in GP, in addition to being detected later. Nevertheless, in LP medium, laccase activity was enhanced during the latter part of the incubation period. In LGP cultures, this activity would probably increase after glucose has been depleted.

It has been proposed that $\mathrm{LiP}$ is the enzyme responsible for the initial attack of lignin because it has higher redox potential than MnP and cleaves bonds between the nonphenolic subunits that are the major component of lignin (Faison and Kirk, 1983). In the present study, LiP activity was found to be enhanced before MnP activity in GP medium and the highest values were recorded for LP 16 days after incubation.

Catalase activity was measured because of the importance of $\mathrm{H}_{2} \mathrm{O}_{2}$ in the process of lignin degradation and catalase might help to protect this fungus against $\mathrm{H}_{2} \mathrm{O}_{2}$, which is a substrate for peroxidases, but $\mathrm{H}_{2} \mathrm{O}_{2}$ could permeate the fungal membrane and, in the presence of metal ions, damage cellular structures, including DNA (Doudican et al., 2005). Faison and Kirk (1983) demonstrated that the addition of catalase to cultures of Phanerochaete chrysosporium inhibits lignin degradation and this could be related to the results reported in the present study.

In L. edodes, it was found that ligninolytic activity was stimulated earlier by adding easily metabolized carbohydrates (Leatham, 1985), so it is possible that, relative to the LP medium, the GP medium tested here 
exerts similar effect on enzyme activity. Nevertheless, in LGP the relationship between the carbon source and the stimulation of enzyme activity was not clear, probably because the presence of lignin modified the environment and the enzymes activity pattern was more complex. It is possible that during incubation, lignin was degraded and liberated several soluble compounds of low molecular weight that modulated the lignin degradation system, which is supported by this work. This effect was suggested by Faison and Kirk (1985) in solid cultures of P. chrysosporium. They found that lignin degradation can be induced by several substrates (or products) including lignin monomers and oligomers. In addition, when white rot fungus is cultivated in lignocellulosic substrates, ligninolytic activity is a secondary metabolic event. Lignin degrading enzymes have different profiles and activity levels depending on the culture system (Ha et al., 2001; Ohga and Royse, 2001).

Although it is thought that white-rot fungus must degrade an alternate substrate in order to carry out lignin depolymerization, some authors have found that organisms hydrolyze polysaccharides at sufficient rates for optimal growth and maintenance of ligninolytic activity (Leatham, 1985; Vane et al., 2003). During delignification, cellulose is broken down simultaneously and hemicellulose is an energy source for white rot fungi, since lignin alone apparently cannot serve as a growth substrate (Elisashvili and Kachlishvili, 2009). Those findings could explain, in part, our data for the LP treatment. Mycelial growth was similar to that of GP throughout the culture, there was no $\mathrm{MnP}$ activity detected, maximum catalase activity was recorded at the end of incubation and LiP was low. Laccase and AAO activity were detected earlier in the culture, though high levels were reached 14 days after inoculation.

Basidiomycetes growing in toxic environments (phenols, resins and other wood components), with limited nutrient availability can successfully compete with other organisms for substrate. Lignin depolymerization is in part achieved by a free radical mechanism based upon the radical generated by peroxidase complexes in the presence of Hydrogen Peroxide $\left(\mathrm{H}_{2} \mathrm{O}_{2}\right.$ produced by gliox-al oxidases and glucose oxidase and aryl alcohol oxidase activities). The fungal enzymes then solubilize lignin, the lignin degradation products (including phenolic monomers) diffuse and the mycelial growth of the fungus accelerates. As a result, more degradation takes place. We feel this is an important tactic for fungi to secure their niche on a substrate before their competitors can. With results obtained here, our next study will focus on whether lignin can be used as carbon source and, if it can, whether that would affect lignin depolymerization.

\section{CONCLUSION}

The present results show that lignin and glucose together supplemented in a liquid culture medium of $L$. edodes enhanced biomass and modified the activity pattern of ligninolytic enzymes, but did not enhance enzyme activity, compared to media without lignin and without glucose. Therefore we propose that this polymer exerts an influence as great as that of a simple carbon source on the activity profile and biomass production of ligninolytic enzymes.

\section{ACKNOWLEDGEMENT}

The researchers thank Dr. Hiroshi Ogura for his valuable suggestions regarding ligninolysis and on the manuscript. A. Gutierrez for his assistance. Citlali Harris-Valle thanks CONACYT for her scholarship.

\section{REFERENCES}

Aro, N., T. Pakula and M. Penttila, 2005. Transcriptional regulation of plant cell wall degradation by filamentous fungi. FEMS Microbiol. Rev., 29: 719739. PMID: 16102600

Beltrán-García, M.J., A. Orozco, I. Samayoa and T. Ogura, 2001. Lignin degradation products from corn stalks enhance notable the radial growth of basidiomycete mushroom mycelia. Rev. Soc. Quím. Méx, 45: 77-81.

Boer, C.G., L. Obici, C.G. Marques de Souza and R.M. Peralta, 2004. Decolorization of synthetic dyes by solid state cultures of Lentinula (Lentinus) edodes producing manganese peroxidase as the main ligninolytic enzyme. Biores. Technol., 94: 107-112. PMID: 15158501

Bradford, M., 1976. A rapid and sensitive method for the quantitation of microgram quantities of protein utilizing the principle of protein-dye binding. Anal. Biochem., 72: 248-254. DOI: 10.1016/00032697(76)90527-3

Busse, N., D. Wagner, M. Kraume and P. Czermak, 2013. Reaction kinetics of versatile peroxidase for the degradation of lignin compounds. Am. J. Biochem. Biotechnol., 9: 365-394. DOI: 10.3844/ajbbsp.2013.365.394

Cohen, G., D. Dembiec and J. Marcus, 1970. Measurement of catalase activity in tissue extracts. Anal. Biochem, 34: 30-38. DOI: 10.1016/00032697(70)90083-7 
Covallazzi, J.R.P., C.M. Kasuya and M.A. Soares, 2005. Screening of inducers for laccase production by Lentinula edodes in liquid medium. Brazilian J. Microbiol., 36: 383-387. DOI: 10.1590/S151783822005000400015

Doudican, N.A., S. Binwei, G.S. Shadel and P.W. Doetsch, 2005. Oxidative DNA damage causes mitochondrial genomic instability in Saccharomyces cerevisiae. Mol. Cell. Biol., 25: 5196-5204. DOI: 10.1128/MCB.25.12.5196-5204.2005

Elisashvili, V. and E. Kachlishvili, 2009. Physiological regulation of laccase and manganese peroxidase production by white-rot Basidiomycetes. J. Biotechnol., 144: 37-42. DOI: 10.1016/j.jbiotec.2009.06.020

Faison, B.D. and T.K. Kirk, 1983. Relationship between lignin degradation and production of reduced oxygen species by phanerochaete chrysosporium. Appl. Environ. Microbiol., 46: 1140-1145. PMID: 16346420

Faison, B.D. and T.K. Kirk, 1985. Factors involved in the regulation of a ligninase activity in phanerochaete chrysosporium. Appl. Environ. Microbiol., 49: 299-304.

Ferrara, M.A., E.P.S. Bon and J.S.A. Neto, 2002. Use of steam explosion liquor from sugar cane bagasse for lignin peroxidase production by Phanerochaete chrysosporium. Appl. Biochem. Biotechnol., 98: 289-299. DOI: 10.1385/ABAB:98-100:1-9:289

Guillén, F. and C.S. Evans, 1994. Anisaldehyde and veratraldehyde acting as redox cycling agents for $\mathrm{H}_{2} \mathrm{O}_{2}$ production by Pleurotus eryngii. Appl. Environ. Microbiol., 60: 2811-2817.

Guillén, F., A.T. Martínez and M.J. Martínez, 1992. Substrate specificity and properties of the aryl alcohol oxidase from the ligninolytic fungus Pleurotus eryngii. Eur. J. Biochem., 209: 603-611. DOI: 10.1111/j.1432-1033.1992.tb17326.x

Guillén, F., B. Gómez-Toribio, M.J. Martínez and A.T. Martínez, 2000. Production of hydroxyl radical by the synergistic action of fungal laccase and aryl alco-hol oxidase. Arch. Biochem. Biophys., 383: 142-147. DOI: 10.1006/abbi.2000.2053

Ha, H.C., Y. Honda and M. Kuwahara, 2001. Production of manganese peroxidase by pellet culture of the lignin-degrading basidiomycete, Pleurotus ostreatus. Appl. Microbiol. Biotechnol., 55: 704711. DOI: $10.1007 / \mathrm{s} 002530100653$

Leatham, G.F., 1985. Extracellular enzymes produced by the cultivated mushroom lentinus edodes during degradation of a lignocellulosic medium. Appl. Environ. Microbiol., 50: 859-867. PMID: 16346918
Mata, G., J.M. Sovoie and P. Delpech, 1997. Variability in laccase production by mycelia of Lentinula borya-na and Lentinula edodes in the presence of soluble lignin derivatives in solid media. Material und Orga-nismen, 32: 109-122.

Moldes, D., M. Lorenzo and M.A. Sanromán, 2004. Different proportions of laccase isoenzymes produced by submerged cultures of Trametes versicolor grown on lignocellulosic wastes. Biotechnol. Lett., 26: 327-330. DOI: 10.1023/B:BILE.0000015452.40213.bf

Ohga, S. and D.J. Royse, 2001. Transcriptional regulation of laccase and cellulase genes during growth and fruiting of Lentinula edodes on supplemented saw-dust. FEMS Microbiol. Lett., 201: 111-115. DOI: $10.1111 /$ j.15746968.2001.tb10741.x

Philippoussis, A., P. Diamantopoulou, K. Papadopoulou, H. Lakhtar and S. Roussos et al., 2011. Biomass, laccase and endoglucanase production by Lentinula edodes during solid state fermentation of reed grass, bean stalks and wheat straw residues. World J. Microbiol. Biotecnol., 27: 285-297. DOI: 10.1007/s11274-010-0458-8

Salmones, D. and G. Mata, 2005. Efecto de la presencia de compuestos solubles sobre la producción de lacasa y biomasa en cultivos de Pleurotus spp. Rev. Mex. Mic., 21: 63-69.

Silva, E.M., A. Machuca and A.M.F. Milagres, 2005. Evaluating the growth and enzyme production from Lentinula edodes strains. Process Biochem., 40: 161-164. DOI: 10.1016/j.procbio.2003.11.053

Tien, M. and K. Kirk, 1984. Lignin-degrading enzymes from Phanerochaete chrysosporium: Purification, characterization and catalytic properties of a unique $\mathrm{H}_{2} \mathrm{O}_{2}$-requiring oxygenase. Proc. Natl. Acad. Sci. USA 81: 2280-2284. DOI: 10.1073/pnas.81.8.2280

Tychanowicz, G.K., A. Zilly, C.G. Marques de Souza and R.M. Peralte, 2004. Decolourisation of industrial dyes by solid-state cultures of Pleurotus pulmo-narius. Process Biochem., 39: 855-859. DOI: 10.1016/S0032-9592(03)00194-8

Vane, C.H., T.C. Drage and C.E. Snape, 2003. Biodegradation of oak (quercus alba) wood during growth of the shiitake mushroom (lentinula edodes): A molecular approach. J. Agric. Food Chem., 51: 947-956. DOI: 10.1021/jf020932h 